\title{
Supervision Practices and Teachers' Satisfaction in Public Secondary Schools: Malaysia and China
}

\author{
Mohd Izham Mohd Hamzah ${ }^{1}$, Yan Wei ${ }^{1}$, Jamil Ahmad ${ }^{1}$, Aida Hanim A. Hamid ${ }^{1}$ \& Azlin Norhaini Mansor ${ }^{1}$ \\ ${ }^{1}$ Universiti Kebangsaan Malaysia, Bangi, Malaysia \\ Correspondence: Azlin Norhaini Mansor, Universiti Kebangsaan Malaysia, Bangi, Malaysia. E-mail: \\ azlinmansor@ukm.my
}

Received: May 3, 2013 Accepted: July 17, 2013 Online Published: July 25, 2013

doi:10.5539/ies.v6n8p92 URL: http://dx.doi.org/10.5539/ies.v6n8p92

\begin{abstract}
The purpose of this study is to explore supervision practices among school management teams and teachers' satisfaction in secondary schools in Kuala Lumpur, Malaysia and He Fei, China. The samples consist of 248 managers and 367 teachers in Kuala Lumpur, and 175 managers and 346 teachers in He Fei. The study indicates that the level of supervision practices in Kuala Lumpur is higher from the managers' standpoint than from the teachers'. Simultaneously, there was no difference between managers' and teachers' view of the level of supervision practices in He Fei. Secondly, supervision practices have a positive and medium relationship to teacher satisfaction in Kuala Lumpur, while there was positive and strong relationship between them in He Fei. In other words, if the level of supervision practices decreases, so will teacher satisfaction. It may therefore be in the interests of both cities' school managers and teachers to increase the levels of supervision practices.
\end{abstract}

Keywords: supervision practices, teachers' satisfaction, staff development, motivating, organizing

\section{Introduction}

Supervision is an important aspect of educational management as it can enhance the quality of educational organizations. It can also draw together discrete elements of instruction into whole-school actions (Glickman \& Gordon \& Ross-Gordon, 2007), reducing the risk of burn-out, enhancing work performance and increasing job satisfaction (Rico, 2010).

In relation to the improvement of instruction, supervision is identical to leadership. Glickman (1985) defines the direct impact of supervision on instructional leadership in terms of five tasks: direct assistance, group development, staff development, curriculum development and action research. Glickman believes that the integration of these tasks unites teachers' needs with the school's goals. Pajak (1990) defines supervision through practice in 12 areas: communication, staff development, instructional programs, planning and change, motivating and organizing, observation and conferencing, curriculum, problem-solving and decision-making, service to teachers, personal development, community relations and research and program evaluation. According to Pajak (1990), these 12 activities are not the responsibility of one individual but of the entire organization. This study adopts Pajak's (1990) viewpoint, since its all-sided definition includes most dimensions of supervision.

Herzberg's (1987) motivation hygiene theory states that there are certain factors in the workplace that foster job satisfaction, while a separate set of factors causes dissatisfaction. On the one hand, achievement, recognition, work itself, responsibility, advancement and growth can motivate staff. On the other, hygiene factors such as policy, supervision, relationship, work conditions, salary and security must be satisfied if they are not to have a negative influence on staff.

\section{Background}

The development of school supervision has been a long and gradual process taking place between the late nineteenth century to the present day. It can be characterized by six representative stages: supervision as inspection, supervision as social efficiency, democratic supervision, scientific supervision, supervision as leadership and clinical supervision.

Despite its long history and evident potential to improve education performance, school supervision remains underdeveloped in both Malaysia and China. The Malaysian Ministry of Education has tabled reforms of several supervision practices, including teacher development and curriculum development. Despite this proposal, 
Malaysian principals have been found to be ignoring their duty as educational supervisors (Nek \& Jamal \& Salomawati, 2000), and little attention has been paid to supervision by school management teams (Suseela, 2007). It is clear that principals need to pay more attention to supervision practices, because these can have a profound influence on other members of school management teams.

While there is no doubt that elements of supervision are practiced in educational organizations in China, they remain discrete, with no holistic, independent and up-to-date system of school supervision. Obviously, this restricts the development of supervision, since its focus is vague and unstable.

The second problem in schools in China is that the function of supervision is inspection rather than guidance or mentoring. This leads to a pattern of educational supervision as measuring, monitoring and even commanding teachers to achieve the scheduled standard, and its emphasis is quantitative, standardized and stylized. The role of guiding or mentoring is almost inexistence (Zhu, Yang \& Cai, 2006).

The third problem is that teachers' satisfaction is ignored. For many years, the Chinese education management has focused merely on teachers' employment, appointment, training and assessment. Teachers' experience of pressure, tension, anxiety and discontent has been neglected (Zhou \& Shi, 2009).

The purpose of this study is therefore to explore and compare the supervision practices of school management teams and teachers' satisfaction in secondary schools in Kuala Lumpur, Malaysia and He Fei, China, paying particular attention to five elements: communication, staff development, instructional programs, motivating and organizing, and curriculum. This study also focuses on the relationship between the supervision practices of school management teams and teachers' satisfaction.

\section{Research Methodology}

In this quantitative study, the sample selection was based on the multistage cluster sampling technique. The sample was made up of representatives from the total number of school managers and teachers in four zones in Kuala Lumpur, Malaysia and He Fei in China. There were 248 managers and 367 teachers selected in Kuala Lumpur, and 175 managers and 346 teachers in He Fei. The sampling distribution of managers and teachers in Kuala Lumpur and He Fei is presented according to zones in Tables 1 and 2.

Table 1. Population of secondary schools managers and teachers in Kuala Lumpur, Malaysia and He Fei, China

\begin{tabular}{llllllll}
\hline $\begin{array}{l}\text { Zones in } \\
\text { KL }\end{array}$ & $\begin{array}{l}\text { No of } \\
\text { schools }\end{array}$ & $\begin{array}{l}\text { No of } \\
\text { managers }\end{array}$ & $\begin{array}{l}\text { No of } \\
\text { teachers }\end{array}$ & Zones in HF & $\begin{array}{l}\text { No of } \\
\text { schools }\end{array}$ & $\begin{array}{l}\text { No of } \\
\text { managers }\end{array}$ & $\begin{array}{l}\text { No of } \\
\text { teachers }\end{array}$ \\
\hline Pudu & 23 & 184 & 2067 & Lu Yang & 8 & 88 & 1013 \\
Bangsar & 23 & 184 & 2065 & ShuShan & 8 & 88 & 904 \\
Sentul & 21 & 168 & 1891 & Yao Hai & 6 & 66 & 539 \\
Keramat & 20 & 160 & 1790 & Bao He & 6 & 66 & 1015 \\
Total & 87 & 696 & 7813 & Total & 28 & 308 & 3471 \\
\hline
\end{tabular}

Table 2. Sample of secondary schools managers and teachers in Kuala Lumpur, Malaysia and He Fei, China

\begin{tabular}{llllllll}
\hline $\begin{array}{l}\text { Zones in } \\
\text { KL }\end{array}$ & $\begin{array}{l}\text { No of } \\
\text { schools }\end{array}$ & $\begin{array}{l}\text { No of } \\
\text { managers }\end{array}$ & $\begin{array}{l}\text { No of } \\
\text { teachers }\end{array}$ & $\begin{array}{l}\text { Zones in } \\
\text { HF }\end{array}$ & $\begin{array}{l}\text { No of } \\
\text { schools }\end{array}$ & $\begin{array}{l}\text { No of } \\
\text { managers }\end{array}$ & $\begin{array}{l}\text { No of } \\
\text { teachers }\end{array}$ \\
\hline Pudu & 10 & 62 & 99 & Lu Yang & 5 & 45 & 87 \\
Bangsar & 10 & 62 & 97 & ShuShan & 5 & 45 & 87 \\
Sentul & 10 & 62 & 89 & Yao Hai & 5 & 45 & 86 \\
Keramat & 10 & 62 & 82 & Bao He & 5 & 40 & 86 \\
Total & 40 & 248 & 367 & Total & 20 & 175 & 346 \\
\hline
\end{tabular}

\subsection{Research Instrument}

Based on Pajak's model (1990), the questionnaire for this research consisted of 70 items based on the five domains of communication, staff development, instructional programs, motivating and organizing and curriculum. Based on Herzberg's model (1987), the questionnaire used to measure teachers' satisfaction with 
supervision practices consisted of 45 items. It is based on the four dimensions of work itself, growth, organizing and relationship.

\subsection{Interpretation of Mean Score}

A five-point Likert type scale was used in this research. The five points are: 1 (Strongly Disagree), 2 (Disagree), 3 (Partially Agree), 4 (Agree) and 5 (Strongly Agree). The levels of mean score were interpreted into five ranges as shown in Table 3.

Table 3. Interpretation of mean score

\begin{tabular}{ll}
\hline Mean score & Interpretation of mean score \\
\hline $1.00-1.80$ & very low \\
$1.81-2.60$ & low \\
$2.61-3.40$ & moderate \\
$3.41-4.20$ & high \\
$4.21-5.00$ & very high \\
\hline
\end{tabular}

Source: Dr. Jamil Bin Ahmad (2012), Faculty of Education, Universiti Kebangsaan Malaysia

\section{Results}

\subsection{Levels of Supervision Practices from Managers' Standpoint}

Based on data from Kuala Lumpur, the level of communication (mean $=4.314$; s.d. $=.464)$ is the highest dimension in the supervision practices, and curriculum (mean $=4.287$; s.d. $=.608)$ is the lowest. In the data from He Fei, the highest dimension is communication (mean $=4.434$; s.d.=. 526) and motivating and organizing (mean $=3.885$; s.d. $=.563)$ is the lowest. Overall finding of Kuala Lumpur shows that members of school management teams feel the supervision practices are at very high level $($ mean $=4.213$; s.d. $=.515)$. In contrast, the overall level of supervision practices (mean $=4.129$; s.d. $=677$ ) in He Fei is lower than in Kuala Lumpur.

Table 4. Levels of supervision practices in Kuala Lumpur, Malaysia and He Fei, China (school management teams)

\begin{tabular}{lllllllll}
\hline & $\begin{array}{l}\text { KL } \\
\mathrm{N}\end{array}$ & Mean & $\begin{array}{l}\text { Std. } \\
\text { deviation }\end{array}$ & $\begin{array}{l}\text { Interpretation } \\
\text { of mean }\end{array}$ & $\begin{array}{l}\text { HF } \\
\mathrm{N}\end{array}$ & Mean & $\begin{array}{l}\text { Std. } \\
\text { deviation }\end{array}$ & $\begin{array}{l}\text { Interpretation } \\
\text { of mean }\end{array}$ \\
\hline Com & 237 & 4.314 & .464 & very high & 175 & 4.434 & .526 & very high \\
SD & 237 & 4.287 & .463 & very high & 175 & 4.273 & .590 & very high \\
IP & 237 & 4.152 & .519 & high & 175 & 4.283 & .572 & very high \\
M \& O & 237 & 4.150 & .516 & high & 175 & 3.885 & .563 & high \\
Curr & 237 & 4.061 & .608 & high & 175 & 3.916 & .759 & high \\
Overall & 237 & 4.213 & .515 & very high & 175 & 4.129 & .677 & high \\
\hline
\end{tabular}

Indicators: Com (Communication), SD (Staff Development), IP (Instructional Programs), M \& O (Motivating \& Organizing), Curr (Curriculum)

\subsection{Levels of Supervision Practices from Teachers' Standpoint}

Table 5 shows teachers' opinions on the levels of supervision practices. In Kuala Lumpur, the means of the five dimensions are similar where the interpretations of mean are at high level, as well as the overall level (mean = 3.705; s.d.=.603) of mean. Meanwhile, from the He Fei data, it is clear that that teachers' opinions of each dimension and overall supervision practices $($ mean $=3.586$; s.d. $=.947)$ are also at high level. 
Table 5. Levels of supervision practices in Kuala Lumpur, Malaysia and He Fei, China (teachers)

\begin{tabular}{lllllllll}
\hline & KL & Mean & $\begin{array}{l}\text { Std. } \\
\text { deviation }\end{array}$ & $\begin{array}{l}\text { Interpretation } \\
\text { of mean }\end{array}$ & $\begin{array}{l}\text { HF } \\
\mathrm{N}\end{array}$ & Mean & $\begin{array}{l}\text { Std. } \\
\text { deviation }\end{array}$ & $\begin{array}{l}\text { Interpretation } \\
\text { of mean }\end{array}$ \\
\hline Com & 302 & 3.778 & .561 & high & 327 & 3.656 & .929 & high \\
SD & 302 & 3.712 & .572 & high & 327 & 3.717 & .935 & high \\
IP & 302 & 3.633 & .619 & high & 327 & 3.708 & .936 & high \\
M \& O & 302 & 3.664 & .617 & high & 327 & 3.757 & .905 & high \\
Curr & 302 & 3.682 & .622 & high & 327 & 3.619 & .910 & high \\
Overall & 302 & 3.705 & .603 & high & 327 & 3.586 & .947 & high \\
\hline
\end{tabular}

Indicators: Com (Communication), SD (Staff Development), IP (Instructional Programs), M \& O (Motivating \& Organizing), Curr (Curriculum)

\subsection{Relationship between Dimensions of Supervision Practices and Teachers' Satisfaction}

Happy workers are productive workers (William, 2012). This study finds that, for better school operation, it is necessary to identify the relationship between supervision practices and teachers' satisfaction.

The correlations between the five dimensions of supervision practices and four dimensions of teachers' satisfaction are analyzed by a Pearson product-moment correlation coefficient, which indicates different strengths of correlations between supervision practices and teachers' satisfaction. This study refers the significant value of $(p<0.05)$ of each dimension from the obtained results. According to Cohen (1977), weak correlation is $r=0.10$ to 0.29 , medium correlation is $r=0.30$ to 0.49 and strong correlation is $r=0.50$ to 1.0 . In Kuala Lumpur, there are strong positive correlations between growth and motivating and organizing $(r=.503)$, compared to growth and other dimensions, which only show moderate correlations. Meanwhile, there are also strong positive correlations between the dimension of organizing and motivating and organizing $(\mathrm{r}=.528)$. However, the correlation between value of dimensions of supervision practices and teachers' satisfaction is higher in He Fei. There are strong positive correlations between work itself and curriculum $(\mathrm{r}=.684)$. There are also strong correlations between growth and curriculum $(\mathrm{r}=.637)$, and finally there is also strong correlations between organizing and curriculum $(\mathrm{r}=.746)$.

\section{Discussion}

\subsection{Overall Supervision Practices}

The findings show that the school managers' mean of supervision practices is higher than the teachers', for both Kuala Lumpur and He Fei. The school managers' higher mean not only shows that their self-evaluation is higher than the teachers' evaluation, but also could express their confidence in their daily work. And since the difference of mean between managers and teachers is not large, it could be considered that managers and teachers hold similar opinions about the level of supervision practices. Overall, it could be conclude that this is a positive phenomenon between managers and teachers in secondary schools in both countries.

\subsection{Dimensions of Supervision Practices}

The emphasis on dimensions of supervision practices differs between managers and teachers, and is also different between the two countries. In Kuala Lumpur, managers consider that the dimension of communication has the highest level and that of curriculum the lowest. This means that managers have strong confidence in communication in their managerial work as compared to the dimension of the curriculum. This study therefore suggests that managers should promote the management of curriculum to support teachers for better supervision practices. Better guidance of curriculum will lead to better teachers' satisfaction. In He Fei, school managers indicate that the dimension of communication has the highest level, thus the perception is the same among school managers in Kuala Lumpur. Effective communication can help us to meet our needs and to feel understood by others (Edmonds, 2011). It is further suggested that effective communication is the life blood of an instructional organization (Mcnamara, 2011). In addition, managers in He Fei feel the dimension of motivating and organizing is the weakest point of their management. This could be strongly related to bureaucratic factors in Chinese societies. On the other hand, in Kuala Lumpur, the dimension of curriculum is found to be the lowest. The standardize curriculum in all schools in Malaysia may need to be contextualize 
according to schools and thus, managers need to put more efforts in guiding the teachers on the curriculum adaptation.

In Kuala Lumpur, the teachers' data shows that their perception of each dimension is at a high level, with the highest-scoring dimension being communication. This corresponds to the managers' perception, meaning that both school managers and teachers feel that communication is at high level in the supervision practices; in other words, teachers agree with the managers' standpoint and acknowledge the managers' abilities in communication. This is a very encouraging finding, since effective communication is a critical characteristic of successful school managers (Halawah, 2005). In He Fei, meanwhile, teachers have different view, in which motivating and organizing are the highest-scoring dimensions, and curriculum the weakest. It is obvious, therefore, that teachers need more guidance by managers about curriculum for better working achievement. Moss (2012) proposed that school managers should guide teachers to better understand the school's rules of curriculum, suitable curriculum plans, useful material, and amiable tone and attitude.

The findings further suggest that some measures should be taken into considerations in order to improve the supervision practices towards better school improvement. First, it is suggested that educational departments should give more authority or power to schools. This is to allow them to reform related procedures of supervision practices. In addition, principals and middle managers must be able to face these changes in term of difficulties and challenges for better supervision practices. Finally, school teachers are suggested to improve their managerial practices and these should be monitored adequately by school managers.

\subsection{Overall Teacher Satisfaction}

Based on the data given, it is found that school managers in these two countries could play a role in making supervision practices function positively. In Kuala Lumpur, it is observed that each dimension of supervision practices has positive relationship with teachers' overall satisfaction. This means that good supervision practices could lead to a high level of teacher satisfaction. In contrast, lack of supervision practices will lead to a low level of teacher satisfaction. In addition, this direct ratio is in the medium level based on Cohen (1977). In He Fei, this study identified that each dimension of supervision practices has positive and strong relationship with teachers' overall satisfaction. The data shows that this relationship is stronger in He Fei than in Kuala Lumpur.

Managers should try their best to improve supervision practices to increase teachers' satisfaction and school efficiency. This is especially the case in He Fei secondary schools, where there is a stronger relationship between supervision practices and teachers' satisfaction. In other words, if the level of supervision practices is low, it will have a greater lowering effect on the level of teachers' satisfaction in He Fei secondary schools than in Kuala Lumpur. This suggests that it is necessary for school managers and educational departments in He Fei to focus more on their supervision practices to achieve better school development.

\subsection{Four Dimensions of Teachers' Satisfaction}

Although there is positive relationship between levels of supervision and teacher job satisfaction in both Kuala Lumpur and $\mathrm{He}$ Fei, the levels of relationship are different, especially between the dimensions of supervision practices and teachers' satisfaction. Thus, this study suggests that secondary schools and educational departments improve their practices and teacher satisfaction based on the data obtained.

In Kuala Lumpur, most of relationships between the dimensions of supervision practices and those of teachers' satisfaction are at medium level. However, some relationships are at strong and weak levels. The dimension of motivating and organizing of supervision practices has a strong relationship with growth and organizing of teachers' satisfaction. Thus, motivating and organizing could be improved by managers, if they hope to increase the level of satisfaction with the aspects of growth and organizing among teachers. School managers should improve the dimension of curriculum so that it will increase the level of teachers' satisfaction with the aspect of organizing. There are three dimensions of supervision practices with weak relationships to teachers' satisfaction. The related dimensions are communication, staff development and instructional programs. This study also suggests that school managers and educational departments amend and update the related content of these three dimensions of supervision practices to achieve a stronger relationship and a higher level of teacher satisfaction. At the same time, all the dimensions of supervision practices and all the dimensions of teachers' satisfaction have strong relationships in He Fei. Thus, the findings of this study could assist secondary schools and educational departments to understand the importance of supervision practices. 


\section{Conclusion}

The quality of supervision practice is a key factor in determining school success. Thus, improving supervision practices by school managers could improve overall educational management and school development, and ultimately lead to school success. This study has examined and compared two cities' public secondary schools. It provides helpful information to the educational sectors in Malaysia and China that may assist in improving supervision practices and the overall quality of educational management.

\section{References}

Cohen, J. (1977). Statistical Power Analysis for the Behavioral Sciences. Revised ed. New York: Academic Press.

Creswell, J. W. (2005). Educational Research. Planning, Conducting, and Evaluating Quatitative and Qualitative Research. In OTED 1083 \& OTED 1085 Qualitative Research Methods Readings. Sydney: Pearson Education Australia.

Edmonds, S. (2011). Barriers to Assertive Communication. Retrieved from http://www.ehow.com/info_8315375_barriers-assertive-communication.html

Glickman, C. D., Gordon, S. P., \& Ross-Gordon, J. M. (2007). Supervision and Instructional Leadership: A Developmental Approach. USA: Pearson Education.

Halawah, I. (2005). The Relationship between Effective Communication of High School Principal and School Climate. Journal of Instructional Psychology, 126(3), 334-345. Project Innovation, Inc. P.O. Box 8508 Spring Hill Station, Mobile, AL 36689-0508.

Herzberg, F. I. (1987). One More Time: How Do You Motivate Employees? Harvard Business Review, Sep/Oct87, 65(5), 109-120.

Krejcie, R. V., \& Morgan, D. W. (1970). Determining Sample Size for Research Activities. Educational and Psychological Measurement, 30, 607-610.

Mcnamara, C. (2011). Free Basic Guide to Leadership and Supervision. Free Management Library. Authenticity Consulting, LLC. Retrieved August 15, 2012, from http://managementhelp.org/management/guidebook.htm\#anchor776411

Moss, L. (2012). How to Plan for Effective Teaching \& Learning. Demand Media. Retrieved August 16, 2012, from http://www.ehow.com/how_7578272_plan-effective-teaching-learning.html

Nek, K. Y. Y., Jamal, N. Y., \& Salomawati, I. (2000). The School Principals' Roles in Teaching Supervision in Selected Schools in Perak, Malaysia. Asian Journal of Business and Management Sciences, 1(2), 50-55.

Pajak, E. (1990). Identification of Dimensions of Supervisory Practice in Education: Reviewing the Literature. Document ED 320285.

Rico. (2010). Supervision. Resilient Individuals, Communities \& Organizations Training, Processes \& Strategies. Retrieved August 20, 2012, from http://www.rico.com.au/training/life_skills/supervision.htm

Suseela, M. (2007). Teacher Learning in Malaysia: Problems and Possibilities of Reform. Kuala Lumpur: University of Malaya.

Williams, R. B. (2012). Are Happy Workers More Productive? Success Systems International, LLC. Retrieved August 23, 2012, from http://www.success.bz/articles/2429/are_happy_workers_more_productive

Zhou, M., \& Shi, D. W. (2009). Investigation of Teachers' Psychology Health in Key Secondary Schools. Educational Theory and Practice, 31.

Zhu, Q., Yang, X., \& Cai, W. Q. (2006). Issues and Analysis: Contemporary Educational Supervision Research. Tian Jin: Educational Press.

\section{Copyrights}

Copyright for this article is retained by the author(s), with first publication rights granted to the journal.

This is an open-access article distributed under the terms and conditions of the Creative Commons Attribution license (http://creativecommons.org/licenses/by/3.0/). 